\title{
Estéticas Contemporâneas: Estudos sobre a pluraliddade artística.
}

Marcos Rizolli

\section{Contemporary Aesthetics: Studies on Artistic Plurality}


Resumo: O presente artigo pretende traçar um panorama das tendências artísticas presentes no mundo contemporâneo. Deseja apresentar uma visão categorizadora das movimentações expressivas que, de projetos individuais, determinam convergências, a saber: estética dos escombros; estéticas neoclassicisantes; estéticas sensoriais. O discurso é historicamente referencial, num procedimento de aglutinação de valores estéticos. Nasce da sintomatologia da vida moderna, perpassa as ações humanas mais sensíveis e viscerais e, alcança o desejo de atualização dos modos harmoniosos da visualidade.

Palavras-chave: Linguagem. Estética. Arte Contemporânea.

Abstract: The present article aims to present a panorama of the existent artistic trends in the world today. It wants to show a categorizing vision of the expressive movements that, from individual projects, determine convergences, as: an aesthetics of debris; neoclassicizing aesthetics; sensorial aesthetics. Discourse is historically referential, in a procedure of agglutination of aesthetic values. It is born of the symptomatology of modern life, goes through the more sensitive, visceral, human actions, and reaches the will to update the harmonious modes of visuality.

Keywords: Language. Aesthetics. Contemporary Arts.

RIZOLLI, Marcos. Estéticas Contemporâneas: estudos sobre a pluralidade artística. Informática na Educação: teoria \& prática, Porto Alegre, v.8, n. 2, p.91-100, jul./dez. 2005. 


\section{Introdução}

Mais do que uma busca de fundamentos estéticos que possam configurar a cultura visual contemporânea, o interesse reflexivo se adere na tentativa de caracterização de três formas de manifestação da plasticidade artística. São elas: a Estética dos Escombros; as Estéticas Neoclassicisantes e as Estéticas Sensoriais.

As duas primeiras expõem, nitidamente, um caráter ideologizante - numa citação aristotélica: seres superiores $x$ seres inferiores - enquanto, os aspectos sensoriais pretendem resgatar, talvez, as mais primitivas percepções humanas.

O propósito está na caracterização e distinção entre essas vertentes atuais do fazer artístico, tentando mostrar suas principais relações com a realidade, com o público espectador e, por fim, dimensionar, através da descrição de tendências representativas, o teor geral de cada estética estudada, em interdisciplinaridade.

Existe, também, a ambição de implicar à pintura e à escultura suas índoles históricas de desbravadoras de novas possibilidades expressivas e estéticas - maneiras práticas de exercitar a filosofia.

Instala-se, aqui, a possibilidade de extensão aos campos aplicativos da arte, os conhecimentos adquiridos em estudos de filosofia e estética.

\section{$2 \quad$ Estética dos escombros}

Projeto de estranhamento, a Estética dos Escombros causa surpresa ao frustrar os conceitos cristalizados de expressão artística e de obra de arte.

Abre-se uma ideologia visual que estabelece a feiúra e o caos do cotidiano - valor típico da contemporaneidade. Uma ordem em declínio que se interessa pela inferioridade da experiência humana. Escombros são vícios torpes e ridículos - e atos ou eventos de deformação.

A Estética dos Escombros refere-se aos entulhos, destroços e ruínas; estrago, derrota, decadência. O feio abala os conceitos tradicionais da arte e quer transformar o próprio sentido da criação artística. Existe a apropriação de mitos e lendas fantásticas e aterrorizantes. A exposição dos horrores da guerra. Cenas doentias. A expressão dos escombros vem para criticar, incomodar e dizer que quanto mais a civilização caminha para o tão desejado futuro, mais escombros (no pensamento, nas ruas, nos projetos) ela encontra. O retrato de uma cultura decadente que precisa ser alertada. Denúncia ecológica. Quebras afetivas e novos costumes - consumo de drogas, perversões e sexualidades desviantes. O medo do futuro processado pela arte: pastiche e humor angustiado. Escombros são fragmentos, resíduos - signos inferiores que deixam suas cicatrizes na paisagem. Imagens deformadas, desproporcionais; negativos; rascunhos. Um ridículo torpor. Um humor mal--humorado, mais próximo da realidade.

Essa estética, contudo, não é tão nova como podemos crer. Embora a tendência de intensificação atual, ela vem aterrorizando todos os tempos e períodos da história da arte e da cultura. Exemplos: os primeiros ensaios técnicos da arte pré-histórica apresentam figuras toscas e primitivas - realizações que denotam a natural falta de habilidade para a construção de imagens e para a operacionalização dos materiais; na Idade Média, constantemente, pinturas expunham mitos e lendas fantásticas e aterrorizantes - 
como podemos reconhecer na produção artística de Bosch; ou, no período Barroco, tempo em que Caravaggio pintava homens pobres e prostitutas - modelos para suas pinturas de santos; Goya é outro artista que se espanta com os horrores da guerra e da revolução - tão bem representado em suas atormentadas gravuras; Van Gogh realiza um auto-retrato sem orelha - uma cena doentia. No século $X X$, o Expressionismo - e suas preocupações - fez surgir os paradigmas que ecoam em nossos dias.

Nessa condução histórica, os próprios artistas nos alertam. Munch, Picasso e Bacon, cada um em seu tempo e ambiente, se aproximam e antecipam a marcha da Estética dos Escombros no mundo pós-modemo.

Assim, hoje, temos:

O medo do futuro é tratado como uma forma de exorcismo. Pastiche e humor tentam esconder a angústia. Há qualquer coisa no ar queremos participar do futuro, mas há uma desconfiança geral. Não estamos nos sentindo muito bem - o desencanto é radical sob o guarda-chuva nuclear. Uma geléia total à beira do caos: em cena a decadência. Um sentimento de vazio e irrealidade se instala. A vida se fragmenta desordenadamente em imagens, dígitos e signos - -tudo leve e sem substância como um fantasma. Entre a apatia e a satisfação, ficamos adormecidos. Nenhuma revolta. O medo do futuro, quase uma tendência da pintura representativa dos escombros, faz surgir, nos suportes, fabulazinhas sem moral nem conclusões. Um mundo em saturação não deve ser questionado quanto ao seu destino. Devemos fingir que brincamos com as convenções e com os costumes.

A Estética dos Escombros pode intervir, também, como um projeto de alerta para a humanidade. Estetiza a violência, o racismo, a cidade - a confusão mundial, cheia de ameaças. Essa vertente de alerta junta os resíduos da cidade: o lixo é índice implacável das sociedades injustas que permitem o acúmulo e encastelamento da riqueza e a exclusão dos destituídos de bens e cultura. As resistências étnicas são complexamente exploradas pelos artistas - as sociedades de economia de primeiro mundo incomodadas pela invasão dos povos de países empobrecidos: negros, amarelos, latinos. Uma forma de alerta e crítica ácida. Alerta-se contra os descasos e desmandos dos governos - educação e saúde precárias; dos abusos policiais e a oficialização da violência; das agressões entre gangues rivais; da violência nos esportes; das aberrações mentais - dos assassinatos em série; da marginalização do ser. O espectro de alerta é amplo - desde as macro-questões presentes nas sociedades aos mínimos eventos do cotidiano - a agressão de crianças, as pequenas perversões que habitam os lares. As sutis violências familiares.

Do alerta à denúncia: um tema fixo - a denúncia ecológica. Quase um projeto de luta incansável -constante, contínuo, barulhento, obsessivo. Poluição de rios, territórios e ar. Matança de animais. Alterações nos ecossistemas. Ameaças tecnológicas e nucleares. A pintura encontra outras formas de manifestações artísticas aliadas: eventos, instalações, performances. Os processos artísticos querem envolver o público em suas causas. Existe uma busca necessária de espaços alternativos. A denúncia não deve ficar confinada - nos limites tradicionais das galerias e museus.

Outra temática é acentuada pela Estética dos Escombros: a crônica dos novos costumes: - drogas, perversões e desvios sexuais. A nova 
moralidade: a imoralidade. Aqui, notamos um confronto - ataque e defesa dos valores e práticas personalizadas. Aquestão das drogas é tratada com um repertório comum e corriqueiro: cigarros, fumaça, caveiras, sangue, seringas de injeção. Morte certa ou deslumbre e alienação garantidos. Imagens lisérgicas. $\mathrm{O}$ universo das perversões é assunto de interesse aproximado aos desvios do comportamento sexual. Tudo o que foge às normas do amor deve ser considerado - possibilidade de aquisição de imagens desconcertantes e agressivas. Homens, mulheres, crianças, animais, seres andróginos se cruzam em atos libidinosos. Masoquismos e sodomias recursos alternativos para o alcance do prazer. Fator carnal.

A Estética dos Escombros é reportagem de seres comuns. Os nós inferiores. Poetizar, aqui, é imitar os homens como eles são: presentes na inferioridade da desordem, da dúvida, ridículos e bizarros. Escombro é resíduo do riso que falta. É imagem de promessa manca: divisível, fragmentária; dada para romper o nexo da ação. Uma catástrofe - ação perniciosa e dolorosa, como são as mortes, as dores, os ferimentos e casos semelhantes. Escombro é comédia de mau- gosto, de fator particular, de pinceladas monstruosas, de cenários risíveis e decadentes. Opção estética pelo inferior e insignificante. Estética da antiarte, acredita na rudeza do real paradigma da necessidade e nega a estrutura do sonho. Arregala os olhos para a violência, a fraqueza e os defeitos. Não há espaço para a paixão mítica. Tudo é perplexidade. O futuro é vulgar, absurdo e, gargalhadamente, comum. A Estética dos Escombros é o retrato da humanidade - que desfaz a obra da natureza, as conquistas das ciências, a sensibilidade da espécie. Humor por saturação. Anestesia: impossibilidade de diálogo.

\section{Estéticas neo-classicisantes}

Estamos no universo da arte figurativa, na dobra entre os anos 80 e 90 . A atualidade do fim do século vinte parece desejar um reviver ideológico. Alguns artistas, pintores e escultores, praticam um retorno - na apreensão de valores visuais já devidamente amalgamados pela história - dos homens e da arte.

Há um novo sopro de criatividade (talvez, o vento que irrompe a Nike de Samotrácia - a escultura alada do período grego helenístico) fazendo, da arte, um novo mito.

Estamos no ambiente das figuras do bem. Seres idealizados. Belos, contemplativos, revestidos de perfeição absoluta: deuses da matéria, preponderantemente, pictórica.

Chamaremos de Estéticas Neoclassicisantes as produções artísticas que optam pela beleza, pela ordem. Elevação. Pintura, aqui, é a imitação de homens superiores. Ornamento, ritmo e harmonia.

Existe nos ateliês, galerias e museus uma mito--poética, ainda, em estágio de execução. Seus artistas estão preocupados com o enigma da criação e fazem desse fenômeno o tema predominante. Constroem e pintam deuses e mitos à sua imitação. Os mais paradigmáticos cânones da figuralidade artística são empregados: proporção; luz e sombra; perspectiva; simetria; fatura cromática; objetividade. Estruturam o belo e o bem e alcançam a harmonia. Estabelecem a criatividade como a mais elevada tarefa dos homens. Deuses, mitos e heróis viventes. $\mathrm{O}$ realismo artístico se dá pela capacidade transcendente, pela narrativa de passagens de vida que modificam a percepção da natureza humana, pela metaforização dos atos. Pintam o mundo e os homens como deveriam ser. 
As Estéticas Neo-classicisantes, em suas catalogadas variações (Classicismo Metafísico; Narrativo; Alegórico; Realista) tendem à sensibilidade clássica. Assim, veremos:

O Classicismo Metafisico encontra seu nexo na paisagem: praças, templos, ambientes urbanos despovoados. Geralmente, seus habitantes são estátuas. O tempo parece ser imutável. A luminosidade é fixa. O silêncio, extraordinário. Essas pinturas têm a capacidade de reter a essência da paisagem urbana. Projeto de citacionismo das construções gregas, das praças italianas. Pintura de arquiteturas. Revisitação de um mestre moderno: De Chirico.

Quando surgem pessoas, adquirem o caráter de personagens de afrescos. Murais que adornam os cantos e interiores das cidades. Ou, então, personagens que se envolvem em lendas e fábulas angelicais - em cenários ajardinados: recantos típicos das periferias das cidades antigas (lazer, prazer e descanso permeados de réplicas de fontes, colunas, esculturas de animais, cupidos, ninfas...).

O Classicismo Narrativo encontra seu repertório de efeitos visuais na arte Pop americana. Os planos pictóricos são recortados, utilizados os recursos das histórias em quadrinhos. Cada quadro narra uma parte da cena visual que, não necessariamente, expõe uma seqüência lógica. Seu campo de ação pode ser desde a montagem aleatória de imagens variadas até a meticulosa narração de um fenômeno ou acontecimento: quadro-aquadro. Seu teor documental, embora quase sempre mentiroso, articula cenas do passado num reviver sincrônico que faz questionar a oficialidade da história. Suas pinturas reportamse a jovens e velhos, a corpos e idéias. Sempre questionando, no espaço pictórico, a passagem do tempo, a superação contínua de valores e ideologias.

O Classicismo Alegórico é crônica visual. Essas pinturas colhem valores composicionais desde Botticelli, passando por David e Manet.

Alimentam-se tanto do drama como do êxtase. O Nu é exponenciado, explorado em todas as suas vicissitudes. A concepção (carnal ou divina) é tema constante. A vida em grupo - 0 coletivo exemplar - é, também, amplamente explorado. Cenas de família, de reuniões, picnics, acampamentos. Cenas femininas nas cozinhas. Homens em alegres conversas nas salas. Casais em aposentos íntimos. Cenas de chás, banquetes, casamentos, danças, bailes. Natureza (humana) viva: crítica.

O Classicismo Realista discute, pictoricamente, o corpo humano em sua nua realidade. É quase um tratado de anatomia poetizado. São deuses - -seres perfeitos.

Segmento mais atualizado do Hiperrealismo, o Classicismo Realista segue os princípios básicos da construção figura clássica. Figuralidade fiel aos cânones gregos da anatomia humana. Esse realismo ideal requer total domínio técnico: desenhos, proporção, cor. Seus pintores mais representativos impõem cortes no campo visual, privilegiando detalhes. Pormenores corporais que fazem alusão à fragmentação das esculturas gregas. Privilegiam o torso.

As figuras são duplos - espelhos que refletem o feminino e o masculino. O curvo e o retilíneo. Contorno e massa. No ápice retiniano, exploram o exagero - poros, pêlos; veias e manchas; músculos, movimentos. A figura humana - em seu teor original e divino abstraída do cenário da natureza: fundos neutros e infinitos. A anatomia humana 
idealizada como exclusividade do olhar.

A mito-poética emoldura o que deveríamos ser: no passado, era a virtude. A pintura é melhor do que a realidade. O espelho reflete o caráter elevado de homens superiores. Nossa natureza é a poesia, sem limite de tempo. O mito é o princípio e nele está a criação. E esta encerra a noção de beleza porque o belo é grandeza e ordem. O todo é hierarquizado princípio, meio e fim. Memória. O mito deve referir-se ao universal. A mito-poética, exposta pelas Estéticas Neo-classicisantes, apresentase como fábula.

Conexão de atos em que o artista, utilizando-se dos dados da tradição, imitando a semelhança dos modelos, os embeleza. A estrutura do mito é um sucesso - um reconhecimento. A arte abre espaço para a paixão, para a virtude do êxtase. Imagina o mito; metaforiza a origem; ornamenta a linguagem; eleva, em discurso e estilo, a criação. A arte, aqui, é uma ação inteira maravilhosamente única.

Assim, o conceito de arte está no sentimento de beleza. Culturalmente, beleza é ordem. As artes gregas e renascentistas ecoam, hoje, no estabelecimento de uma arte de construção ideal -bela e ilusória, réplica da realidade intelectual.

\section{$4 \quad$ Estéticas sensoriais}

Diz-se de um instante de abstração em que o ser latente, no percurso de hominização, descolou-se da natureza - o universo sensível. $\mathrm{E}$, assim, abriu um hiato entre ele e a paisagem. Este ambiente; o da percepção distanciada, acabou sendo ocupado pelas linguagens e, na dobra do tempo e do espaço, passamos a construir nossa própria realidade. Instaurou-se a consciência. Numa atitude de compreensão dos fenômenos, transformamos o todo em partes: objetos de significação - um universo de segunda geração. Um segundo momento de abstração: o mundo paralelo da arte.

É no contexto criação (original) - ser criação (artística) que as Estéticas Sensoriais tentam movimentar-se. O interesse está na íntima relação matéria-e-forma, numa busca de resgate de sensações qualitativas que recoloquem o homem em contato com o mundo natural.

Em nosso século, contrárias ao acinzentamento das grandes cidades e ao teor de artificialismo que reveste e filtra a existência contemporânea, nos anos 60 , surgem duas significativas tendências de arte que, cada qual em sua lógica de manifestação, vão inaugurar as preocupações técnicas e estéticas da sensorial idade. São elas: a Land Arte a Body Art.

A Land Art, interferindo na natureza, fez com que os espaços naturais e também as paisagens alteradas industrialmente se convertessem em material de configuração artística. Em ambientes distantes e despovoados da Terra - desertos, lagos, geleiras, montanhas - artistas escavaram significados, traçaram linhas sobre o terreno, tingiram superfícies, empilharam pedras -reordenando os lugares. Hoje, se mostram como registros efêmeros da presença do homem e da artisticidade em regiões vazias, silenciosas e neo-religiosas - a ecologia.

As ações de Land Artforam interferências de protesto contra a estética do plástico e do metal, contra a polida perfeição industrial. No âmbito da produção escultórica, os artistas utilizaram a vastidão dos espaços naturais como verdadeiro objeto artístico. Espaços que o sentido privilegiado do olhar não conseguiria 
controlar.

Influenciada pelos ornamentos corporais dos povos em estágio primitivo, a Body Art, assim como a Land Art, propõe a eliminação de suportes tradicionais de aplicação expressiva. Artistas dispõem do próprio corpo para construir significações. Originam-se novas atitudes de pintura corporal. A exposição do corpo nu faz aparecer um conjunto de manifestações que apontam para um retorno ao primitivo - o naturismo (deslocado dos ambientes de lazer e trazido para os espaços de fruição artística) exige o estreitamento das relações do espectador com a obra de arte. ABody Art requer o toque, o gesto, a intervenção do público.

Transitando entre uma memória suave e nostálgica da organicidade humana e as mais agressivas e constrangedoras situações, por vezes, o corpo se mostra ferido, amarrado, excrementado, cru e, num paradoxo, poeticamente belo.

Land Arte Body Art, na continuidade de seus fenômenos, em união, irão promover a multiplicidade de eventos e tendências que vão recorrer à totalidade sensorial. Assim, definese um conjunto intelectual que tenta rastrear elou dar lastro teórico às inúmeras manifestações perceptórias dos sentidos humanos, solicitados isoladamente ou em exigências combinadas. Além do olhar - no que tange às artes plásticas - a audição, o olfato, o paladar e, principalmente, o tato serão retirados da condição de dormência e exigidos ao grau máximo de suas potencialidades.

Em síntese, delineia-se um inventário de tendências sensoriais e suas breves definições, justamente para que se perceba a diversidade expressiva. Asaber:
AArte Objetual - em suas combinatórias projetivas; as Instalações - que provocam interação e deslocamento no espaço; as Performances - integrando o público na ação; a Pintura Matérica - oferecendo toda sedução material; a Arte Processual - que exige do espectador o fator de conclusão e finalidade da obra de arte; o Cinetismo - pinturas ou esculturas que desafiam o teor retiniano das artes plásticas; Colagem e Assemblagem - na tarefa de reapresentação de imagens prontas; a Pintura de Ação - e seu exponenciamento textural; o Tachismo - e o gesto pictórico registrado na matéria; o Ajuntamento - e a incômoda reorganização do espaço dado por peças de repetição modular; a Combine Painting - nos atos de pintar, colar, costurar, reter; o Contra-relêvo -na permanente mecânica de focagem e desfocagem; a Tela Recortada - que desmancha a lógica retangular dos suportes pictóricos, indo se relacionar desavisadamente com a parede; a Eat-Art-que encerra sua função a partir do consumo gastronômico da obra de arte; a Empaquetage -que reveste de pele artificial objetos, construções e paisagens; a Soft-sculpture - e o acariciamento dos sentidos; a Frottage - técnica de raspagem que redescobre superfícies e camadas internas; a Piquage - retalhando a lógica e recompondo a percepção...e toda sorte de procedimentos artísticos atentos à apreensão total dos sentidos humanos oferecem o tom da amplitude e abrangência dessa fértil vertente da arte contemporânea.

O abandono de suportes e de técnicas convencionais desacomodaram os demais sentidos, além do olhar. Essa nova tipologia artística exige do espectador disponibilidade, ação, interatividade. Essas proposições sensoriais precisam de que os vários canais sensoriais cooperem entre si dando lugar a um contínuo indiferenciado. 
São novas técnicas de imagem que querem alargar a efetiva classificação das artes - abrindo-se possibilidades de variação, no âmbito da estética, da sensorialidade. Os sentidos seriam os dispositivos de interação com o mundo. Os sentidos renunciam à sua separação e interferem entre si. As experiências estéticas consomem-se vivendo-as. A diferença entre o produtor e o espectador é diluída. A distância entre a natureza (material) e o signo é menor.

As Estéticas Sensoriais investem na total dimensão dos sentidos, propondo o encaminhamento para o simbólico.

Manifesta-se um movimento de restauração de uma distante totalidade dos sentidos. Da supremacia do olhar, surgem outras formas sensoriais: táteis, sonoras e olfativas que, aptas para inaugurar novas imagens, capitaneiam uma nova forma de apreender a realidade cotidiana. Nas artes, cada vez mais, os sentidos se cruzam e se articulam em possibilidades plurais da ação expressiva. As artes plásticas, num encaminhamento pós-moderno, vêm oferecendo uma significativa aproximação entre objeto e espectador.

A integração de todos os sentidos têm sido desafio e meta de um segmento de artistas que abrem tendências que devem ser analisadas no âmbito das estéticas sensoriais. Da situação da cultura atual, as Estéticas Sensoriais buscam a extração de um campo aberto de trabalho e reflexão.

Não se trata de elaborar um retomo à razão empirista, como Locke e Hume propuseram, mas sim aproveitar a noção de que seja possível determinar o conhecimento humano a partir, também, da experiência sensível. Cognição que se refere à experiência, às sensações e às percepções: sensação inata.

Da experiência de selecionar materiais que pudessem ser transformados, nossos ancestrais souberam conferir novos significados: extraídos da natureza. De sua admirável relação com os elementos. Ao triturar ossos, minerais, cascas e sementes, descobriu os pigmentos; fez o fogo endurecer o barro modelado; com gravetos e tufos de pêlos de animais, criou toscos pincéis. Alterou, assim, com os instrumentos e os objetos recursos da hominização - a paisagem, o cotidiano, a vida.

Assim, a imaginação criadora, em sua condenação de liberdade, carrega o signo da complexidade: ato intencional, interferente no real que, dado à experiência, remete a conceitos. Noções de artisticidade, extraídas da intervenção de objetos físicos: as artes plásticas.

O fenômeno da multiplicidade das artes, numa forma de abordagem que privilegia a consistência material, prepara o surgimento, na contemporaneidade, de manifestações artísticas que sugerem a formulação de uma nova posição estética ou, na pluralidade dos acontecimentos: as estéticas sensoriais.

\section{Conclusão}

Caracterizadas e imagetizadas as três formas estéticas pesquisadas, devemos, agora, indicar um ponto de ligação entre elas.

Quando, na introdução do trabalho, alertamos para as presenças da pintura e da escultura, como modalidades de nossa atenção teórico-prática, salientamos que o nexo geral que promove o surgimento - e irreversível desenvolvimento - das estéticas dos Escombros, Neo-classicisantes e Sensoriais, se dá pela tarefa de resistência a uma quarta possibilidade estética presente no mundo 
contemporâneo: as Estéticas Tecnológicas, derivadas da relação homem - máquina.

Esse confronto - antes de ser a mediação de capacidades de construção da obra de arte, abordagem sobre o campo técnico e material, a solicitação do público, a legitimação do mercado, os desafios de ocupação dos espaços artísticos -é, sem dúvida, uma questão filosófica. Modos e posturas diferenciadas acerca do entendimento da existência humana e o fenômeno das artes.

A Estética dos Escombros fala dos dejetos - pensamento e matéria - que a sociedade industrial e informatizada produz. As Estéticas Neo-Classicisantes abrem citações à cultura do artesanato - o ambiente do fazer manual. As Estéticas Sensoriais querem reverter o quadro dos sistemas matêmicos, no recondicionamento da matéria sensível.

\section{Referências}

BAYER, R. História da Estética. Lisboa: Estampa, 1979.

BARILLI, R. Curso de Estética. Lisboa: Estampa, 1994.

CHIPP, H.B. Teorias da Arte Moderna. São Paulo: Martins Fontes, 1988.

COCHOFEL, J.J. Iniciação Estética. Lisboa: Europa-América. (s.d.)

EAGLETOM, T. A Ideologia da Estética. Rio de Janeiro: Jorge Zahar, 1993.

HONNEF, K. Contemporary Art. Berlin: Taschen, 1988.

JENCKS, Ch. Post-Modernism. New York: Rizzoli, 1987.

LUCIE-SMITH, E. El Arte Hoy. Madrid: Cátedra, 1983.

MORAIS, F. Panorama das Artes Plásticas. São Paulo: Instituto Cultural Itaú, 1989.

NUNES, B. Introdução à Filosofia da Arte. São Paulo: Ática, 1989.

PAPADAKYS, A. New Art. Londres: Academy Editions, 1991.

PAREYSON, L. Os Problemas da Estética. São Paulo: Martins Fontes, 1989.

SANTAELLA, L. Estética de Platão a Peirce. São Paulo: Experimento, 1994.

SANTOS, J.F. O que é Pós-Moderno. São Paulo: Brasiliense, 1986.

THOMAS, K. Diccionário del Arte Actual. Barcelona: Labor, 1982.

Recebido em novembro de 2005

Aceito para publicação em dezembro de 2005

Marcos Rizolli

Universidade Presbiteriana Mackenzie;

Programa de Pós-Graduação em Educação,

Arte e História da Cultura. Grupo de Pesquisa:

Arte e Linguagens Contemporâneas.

E-mail:marcosrizolli@mackenzie.com.br; rzll@uol.com.br. 